\title{
Efficacy and tolerability of adjunctive lacosamide in pediatric patients with focal seizures
}

Viktor Farkas, MD, Barbara Steinborn, MD, PhD, J. Robert Flamini, MD, Ying Zhang, MS, Nancy Yuen, PharmD, Simon Borghs, MSc, Ali Bozorg, MD, Tony Daniels, BS, Paul Martin, PhD, Hannah C. Carney, PhD, Svetlana Dimova, MD, PhD, and Ingrid E. Scheffer, MBBS, PhD, on behalf of the SP0969 Study Group

Neurology ${ }^{\circledR}$ 2019;93:e1212-e1226. doi:10.1212/WNL.0000000000008126

\section{Abstract}

\section{Objective}

To evaluate efficacy and tolerability of adjunctive lacosamide in children and adolescents with uncontrolled focal (partial-onset) seizures.

\section{Methods}

In this double-blind trial (SP0969; NCT01921205), patients (age $\geq 4-<17$ years) with uncontrolled focal seizures were randomized (1:1) to adjunctive lacosamide/placebo. After a 6-week titration, patients who reached the target dose range for their weight $(<30 \mathrm{~kg}: 8-12 \mathrm{mg} / \mathrm{kg} / \mathrm{d}$ oral solution; $\geq 30-<50 \mathrm{~kg}$ : $6-8 \mathrm{mg} / \mathrm{kg} / \mathrm{d}$ oral solution; $\geq 50 \mathrm{~kg}$ : 300-400 mg/d tablets) entered a 10 -week maintenance period. The primary outcome was change in focal seizure frequency per 28 days from baseline to maintenance.

\section{Results}

Three hundred forty-three patients were randomized; 306 (lacosamide 152 of 171 [88.9\%]; placebo 154 of 172 [89.5\%]) completed treatment (titration and maintenance). Adverse events (AEs) were the most common reasons for discontinuation during treatment (lacosamide 4.1\%; placebo 5.8\%). From baseline to maintenance, percent reduction in focal seizure frequency per 28 days for lacosamide $(\mathrm{n}=170)$ vs placebo $(\mathrm{n}=168)$ was $31.7 \%(p=0.0003)$. During maintenance, median percent reduction in focal seizure frequency per 28 days was $51.7 \%$ for lacosamide and $21.7 \%$ for placebo. Fifty percent responder rates ( $\geq 50 \%$ reduction) were $52.9 \%$ and $33.3 \%$ (odds ratio 2.17, $p=0.0006$ ). During treatment, treatment-emergent AEs were reported by $67.8 \%$ lacosamide-treated patients (placebo $58.1 \%)$, most commonly $(\geq 10 \%)$ somnolence (14.0\%, placebo $5.2 \%$ ) and dizziness (10.5\%, placebo $3.5 \%$ ).

\section{Conclusions}

Adjunctive lacosamide was efficacious in reducing seizure frequency and generally well tolerated in patients (age $\geq 4-<17$ years) with focal seizures.

\section{ClinicalTrials.gov identifier:}

NCT01921205.

\section{Classification of evidence}

This trial provides Class I evidence that for children and adolescents with uncontrolled focal seizures, adjunctive lacosamide reduces seizure frequency.

\author{
Correspondence \\ Dr. Farkas \\ farkas.viktor@ \\ med.semmelweis-univ.hu
}

\section{MORE ONLINE}

$\rightarrow$ Class of Evidence

Criteria for rating

therapeutic and diagnostic studies

NPub.org/coe 


\section{Glossary}

$\mathbf{A E}=$ adverse event; $\mathbf{A E D}=$ antiepileptic drug; $\mathbf{B R I E F}=$ Behavior Rating Inventory of Executive Function; $\mathbf{C B C L}=\mathrm{Child}$ Behavior Checklist; $\mathbf{C I}=$ confidence interval; ILAE = International League Against Epilepsy; LS = least squares; $\mathbf{M H D}=$ 10-hydroxycarbazepine; SCB = sodium channel-blocking; TEAE = treatment-emergent adverse event.

Approximately $25 \%$ to $30 \%$ of children with epilepsy have uncontrolled seizures despite antiepileptic drug (AED) treatment ${ }^{1}$; therefore, novel AED therapies are sorely needed. Lacosamide is an AED that exerts its anticonvulsant activity by selectively enhancing slow inactivation of voltage-gated sodium channels. ${ }^{2}$ It has a predictable pharmacokinetic profile with a high oral bioavailability and a low potential for clinically relevant pharmacokinetic drug-drug interactions. ${ }^{3}$ Lacosamide is indicated for the treatment of focal (partial-onset) seizures in patients $\geq 4$ years of age in the United States and the European Union.

The efficacy, safety, and tolerability of lacosamide as adjunctive therapy and monotherapy for adults with focal seizures have been demonstrated in several randomized controlled trials $^{4-9}$ and are further supported by clinical practice experience. ${ }^{10-12}$ The use of adjunctive lacosamide in children and adolescents has been investigated in open-label trials ${ }^{13,14}$ and reported in observational studies. ${ }^{15-20}$ The objective of this randomized, double-blind, placebo-controlled trial was to evaluate the efficacy and tolerability of adjunctive lacosamide in children and adolescents $(\geq 4-<17$ years of age) with uncontrolled focal seizures.

\section{Methods}

\section{Standard protocol approvals, registrations, and patient consents}

The trial was conducted in accordance with good clinical practice and the Declaration of Helsinki. The protocol and amendments were reviewed by a national, regional, or independent ethics committee or institutional review board. Each patient (when able to assent) and the parent or legal guardian provided written informed consent. The trial was registered with ClinicalTrials.gov (NCT01921205).

\section{Patients}

SP0969 was a randomized, double-blind, placebo-controlled trial conducted at 114 sites in Europe, North America, Latin America, and the Asia Pacific region. Eligibility criteria were assessed by the investigators at the screening visit. Children and adolescents $(\geq 4-<17$ years of age $)$ were eligible for enrollment if they had a diagnosis of epilepsy with focal (partialonset) seizures, with $\geq 1$ prior EEG and MRI/CT scans consistent with this diagnosis. Additional inclusion criteria were uncontrolled focal seizures after an adequate course of treatment (in the opinion of the investigator) with $\geq 2$ AEDs (concurrently or sequentially); an average of $\geq 2$ focal seizures per 28 days, with no more than 21 days without seizures in the 8-week period before entering the baseline period, and at least 2 focal seizures during the 8-week prospective baseline; and a stable dose regimen of 1 to 3 AEDs for $\geq 4$ weeks before the baseline period and throughout the trial. Exclusion criteria included assignment to lacosamide in a previous trial or participation in a trial of another investigational medical product or device within the previous 2 months; convulsive status epilepticus (within the previous 2 months); Lennox-Gastaut syndrome; primary generalized epilepsy; mixed seizure disorder (focal [partial] and primarily generalized seizures); exclusively febrile seizures; nocturnal seizures only; or epilepsy secondary to a progressive cerebral or neurodegenerative disease (additional criteria in supplemental Methods available from Dryad, doi.org/10.5061/dryad.kt5jj49).

\section{Trial design}

The trial consisted of an 8-week prospective baseline period, 16-week treatment period (6-week titration, 10-week maintenance), 4-week taper/transition period, and a 30-day safety follow-up period for patients not entering the open-label extension trial (EP0034; NCT01964560) (figure 1). Eligible patients were randomized (1:1) to lacosamide or placebo.

Trial medication was administered orally twice daily at $\approx 12$ hour intervals. Patients weighing $<50 \mathrm{~kg}$ initiated lacosamide or matching placebo at a dose of $2 \mathrm{mg} / \mathrm{kg} / \mathrm{d}$ (oral solution), and those weighing $\geq 50 \mathrm{~kg}$ had a starting dose of $100 \mathrm{mg} / \mathrm{d}$ (tablets) (figure 1). Patients weighing $\geq 50 \mathrm{~kg}$ who were unwilling or unable to swallow tablets took the oral solution. A dosing syringe was used to ensure accurate administration of the oral solution. Administration of oral solution by feeding tube was permitted if needed.

After the first week of treatment, the investigator determined whether the patient could tolerate a dose increase or should remain on the current dose. Doses were increased in weekly increments of $2 \mathrm{mg} / \mathrm{kg} / \mathrm{d}$ (oral solution; patients weighing $<50 \mathrm{~kg}$ ) or $100 \mathrm{mg} / \mathrm{d}$ (tablets; patients weighing $\geq 50 \mathrm{~kg}$ ), with unlimited dose holds and/or back-titration permitted at the investigator's discretion. The target dose range for each patient was based on body weight at baseline: 8 to $12 \mathrm{mg} / \mathrm{kg} /$ $\mathrm{d}$ for $<30 \mathrm{~kg}, 6$ to $8 \mathrm{mg} / \mathrm{kg} / \mathrm{d}$ for $\geq 30 \mathrm{~kg}$ to $<50 \mathrm{~kg}$, and 300 to $400 \mathrm{mg} / \mathrm{d}$ for $\geq 50 \mathrm{~kg}$. Patients who were not able to reach the minimum target dose by the end of the 6-week titration period were withdrawn. No further dose adjustments were permitted during the 10-week maintenance period. Patients who completed the maintenance period had the option of transitioning to an open-label extension trial or tapering off their trial medication. 


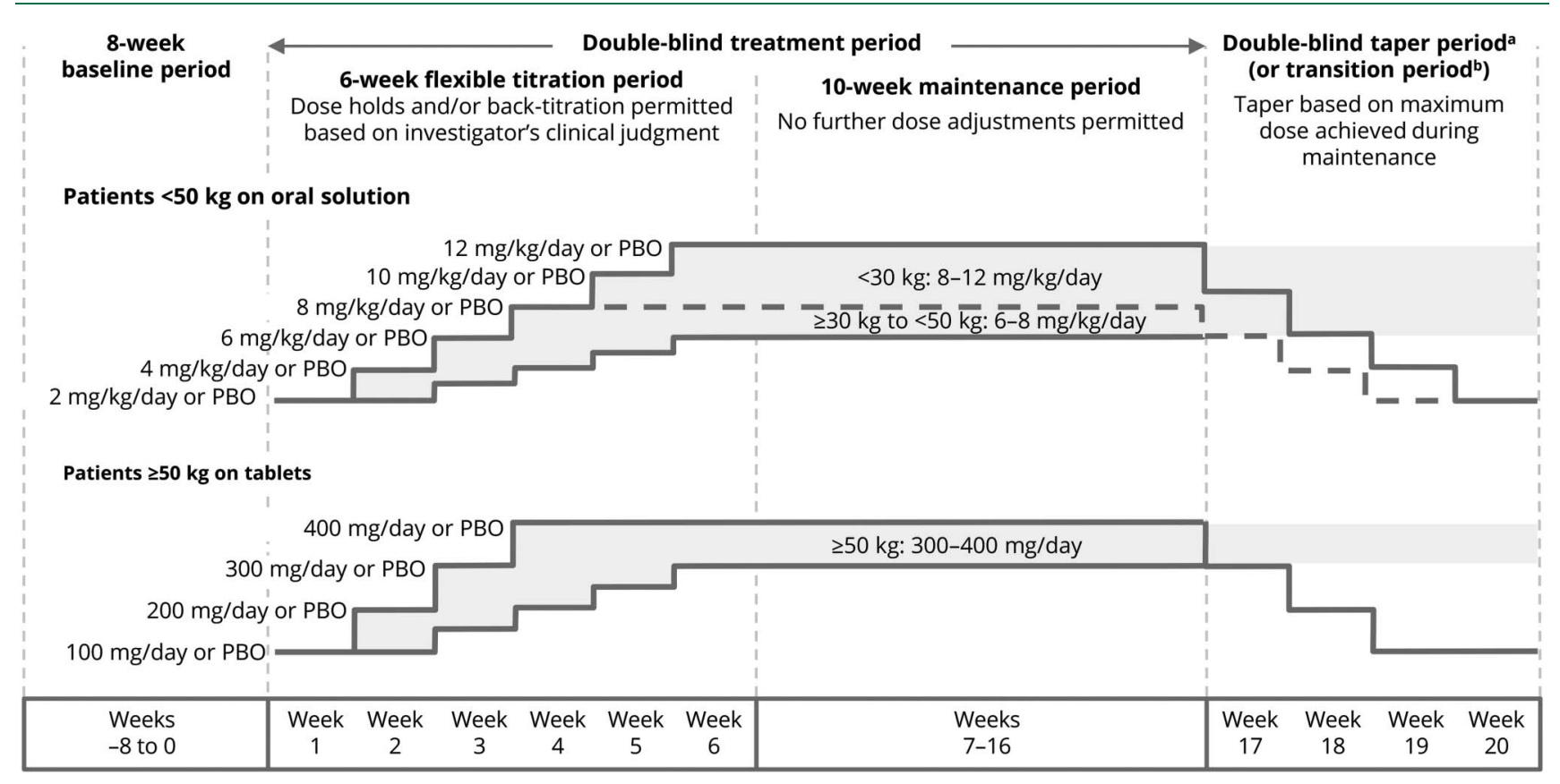

PBO = placebo. ${ }^{\text {a }}$ The highest possible dose per body weight category is shown for each taper period week. ${ }^{\mathrm{b}}$ Patients on lacosamide remained on their maintenance dose during the transition period, whereas patients in the placebo group initiated lacosamide in a double-blind fashion. On completion of the transition period, eligible patients entered the open-label extension on a weight-based dose (<30 kg: 10 mg/kg/d; $\geq 30-<50 \mathrm{~kg}: 6 \mathrm{mg} / \mathrm{kg} / \mathrm{d}$; $\geq 50 \mathrm{~kg}$ : $300 \mathrm{mg} / \mathrm{d}$ ).

Patients attended weekly trial visits throughout the titration period and fortnightly visits thereafter. Throughout the trial, patients and/or their caregivers completed a daily diary of seizure activity (type and frequency). Diaries were checked by the investigators at each visit to ensure accurate and thorough completion and were used to assess efficacy outcomes. Per the trial protocol, seizure types were defined according to the International League Against Epilepsy (ILAE) 1981 criteria as simple partial (focal aware according to the ILAE 2017 classification), complex partial (focal impaired awareness), and partial evolving to secondarily generalized (focal to bilateral tonic-clonic). ${ }^{21,22}$

\section{Outcome variables}

The primary efficacy outcome was the change in focal seizure frequency per 28 days from baseline to maintenance. Secondary outcomes were the change in focal seizure frequency per 28 days from baseline to the entire treatment period (titration and maintenance combined), assessed overall and by focal (partial) seizure subtype (simple partial, complex partial, secondarily generalized); patients with a $\geq 50 \%$ reduction in focal seizure frequency ( $50 \%$ responders; maintenance); patients with a $\geq 25 \%$ increase in focal seizure frequency per 28 days (treatment); the proportion of seizure-free days (maintenance); and the proportion of patients who completed maintenance without a seizure (achieved seizure-free status). Other efficacy outcomes (assessed post hoc) were the median percent reduction from baseline in focal seizure frequency per 28 days (maintenance and treatment), 50\% responders during treatment, and patients with a $\geq 75 \%$ reduction in focal seizure frequency (75\% responders; maintenance and treatment).

Safety outcomes included the incidences of treatmentemergent adverse events (TEAEs), discontinuations due to TEAEs, shifts from baseline to last visit in assessments of behavior and cognitive function (Achenbach Child Behavior Checklist [CBCL]; Behavior Rating Inventory of Executive Function [BRIEF]/BRIEF-Preschool version), clinical laboratory evaluations, ECG and vital sign monitoring, and physical and neurologic examinations. The time to onset, dose at onset, and duration of somnolence and dizziness were also assessed.

Pharmacokinetic outcomes included plasma concentrations of lacosamide and concomitant AEDs based on blood samples at the screening visit, final titration and maintenance visits, and/or early termination visit. Post hoc analyses of pharmacokinetic data were performed to evaluate the plasma concentrations of concomitant AEDs during adjunctive lacosamide treatment.

\section{Statistical analyses}

Efficacy analyses comprised the full analysis set of all randomized patients who received at least 1 dose of trial medication and who had a baseline and at least 1 postbaseline assessment of seizure frequency data. Randomized patients who received at least 1 dose of trial medication were included in safety analyses (safety set). Patients who had at least 1 measurable postdose plasma sample (plasma level above the 
limit of quantification, with documented sampling and medication intake times) were included in pharmacokinetic analyses (pharmacokinetic-per-protocol set).

The trial was powered to detect a significant difference from baseline to maintenance between lacosamide and placebo in focal seizure frequency per 28 days. One hundred thirty-five patients per treatment arm were necessary to detect an effect size of 0.342 (placebo-subtracted difference of -0.249 and a common SD of 0.73 on the log-transformed data, equivalent to $\approx 22 \%$ reduction over placebo after exponentiation) with a power of $80 \%$ and a 2 -sided test at a significance level of $5 \%$. With this sample size, a 2 -sided continuity-corrected $\chi^{2}$ test at a significance level of $5 \%$ will provide $\approx 87 \%$ power for assessment of the $50 \%$ responder rate, assuming responder rates of $22 \%$ and $40 \%$ for the placebo and lacosamide groups, respectively. To account for an anticipated dropout rate of $\approx 14 \%$, 308 patients were planned for enrollment (154 per treatment arm). During the trial, a blinded re-estimation of sample size was performed, and the target for randomization was increased to 340 patients (supplemental Methods available from Dryad, doi.org/10.5061/dryad.kt5jj49).

Assessments of focal seizure frequency per 28 days were based on the number of days for which seizure information was provided during the specified time interval. If $>10 \%$ of the diary entries were missing for a specific patient and time interval, then that patient was not included in the analyses of seizure frequency or seizure-free days during that time interval. For those who discontinued before maintenance, all available seizure frequency data from the titration period were carried forward for the maintenance period analysis. Similarly, for patients who discontinued during maintenance, all available seizure frequency data were used for the calculation of seizure frequency per 28 days during the maintenance period.

For the primary outcome, an analysis of covariance was performed on log-transformed seizure frequency with terms for treatment and pooled center and log-transformed baseline seizure frequency as a covariate. The change in focal seizure frequency for lacosamide vs placebo during maintenance was compared using least squares (LS) means, and the percent reduction over placebo was estimated. The change in focal seizure frequency per 28 days during treatment and the proportion of seizure-free days during maintenance (days with no seizures/days with lacosamide, per patient diary) were analyzed with similar methods. Responder rates were analyzed with a logistic regression model with terms for treatment and pooled center, and odds ratios with $95 \%$ confidence intervals (CIs) were calculated. Patients who discontinued before maintenance were treated as nonresponders. Descriptive analyses were performed for all other efficacy and safety outcomes.

Post hoc subgroup analyses of efficacy outcomes were performed by focal seizure subtype (including the combined category of complex partial and/or secondarily generalized seizures) and by concomitant use of sodium channelblocking (SCB) AEDs (carbamazepine, lamotrigine, oxcarbazepine, phenytoin, and rufinamide). Post hoc subgroup analyses of TEAE data were performed by number of concomitant AEDs, and by concomitant SCB use.

Patients were included in post hoc analyses of plasma levels of concomitant AEDs if they were on a stable dose regimen of valproic acid, levetiracetam, lamotrigine, carbamazepine, topiramate, oxcarbazepine, clonazepam, or clobazam and had plasma levels above the lower limit of quantification for the selected AEDs at baseline and at least 1 postbaseline visit during treatment. For patients on oxcarbazepine, the plasma concentration of the main oxcarbazepine active metabolite 10-hydroxycarbazepine (MHD) was assessed. Patients who received $>1$ concomitant AED were counted once within each AED category. Repeated-measures analysis of covariance was performed, and geometric LS mean ratios (treatment/ baseline) with $90 \%$ CIs were estimated for plasma concentrations. No lacosamide effect on AED concentration was concluded if the $90 \%$ CIs of the geometric LS means ratios were within the bioequivalence limit of 0.8 to 1.25 .

\section{Data availability}

Underlying data from this manuscript may be requested by qualified researchers 6 months after product or indication approval in the US and/or Europe, or global development is discontinued, and 18 months after trial completion. Investigators may request access to anonymized individual patient data and redacted study documents, which may include raw datasets, analysis-ready datasets, study protocol, blank case report form, annotated case report form, statistical analysis plan, dataset specifications, and clinical study report. Before use of the data, proposals need to be approved by an independent review panel at www.clinicalstudydatarequest.com and a signed data sharing agreement will need to be executed. All documents are available in English only, for a prespecified time, typically 12 months, on a password-protected portal.

\section{Classification of evidence}

Primary research question was the following: is adjunctive lacosamide efficacious in reducing focal seizure frequency in children and adolescents with uncontrolled focal seizures?

This trial provides Class 1 evidence that adjunctive lacosamide reduced focal seizure frequency by $31.72 \%$ vs placebo $(p=0.0003)$.

\section{Results}

\section{Patients}

The trial was performed between August 2013 and January 2017. Three hundred forty-three patients were randomized, of whom 306 completed the treatment period and 302 completed the trial (figure 2). Adverse events (AEs) were the most common reasons for trial discontinuation during 


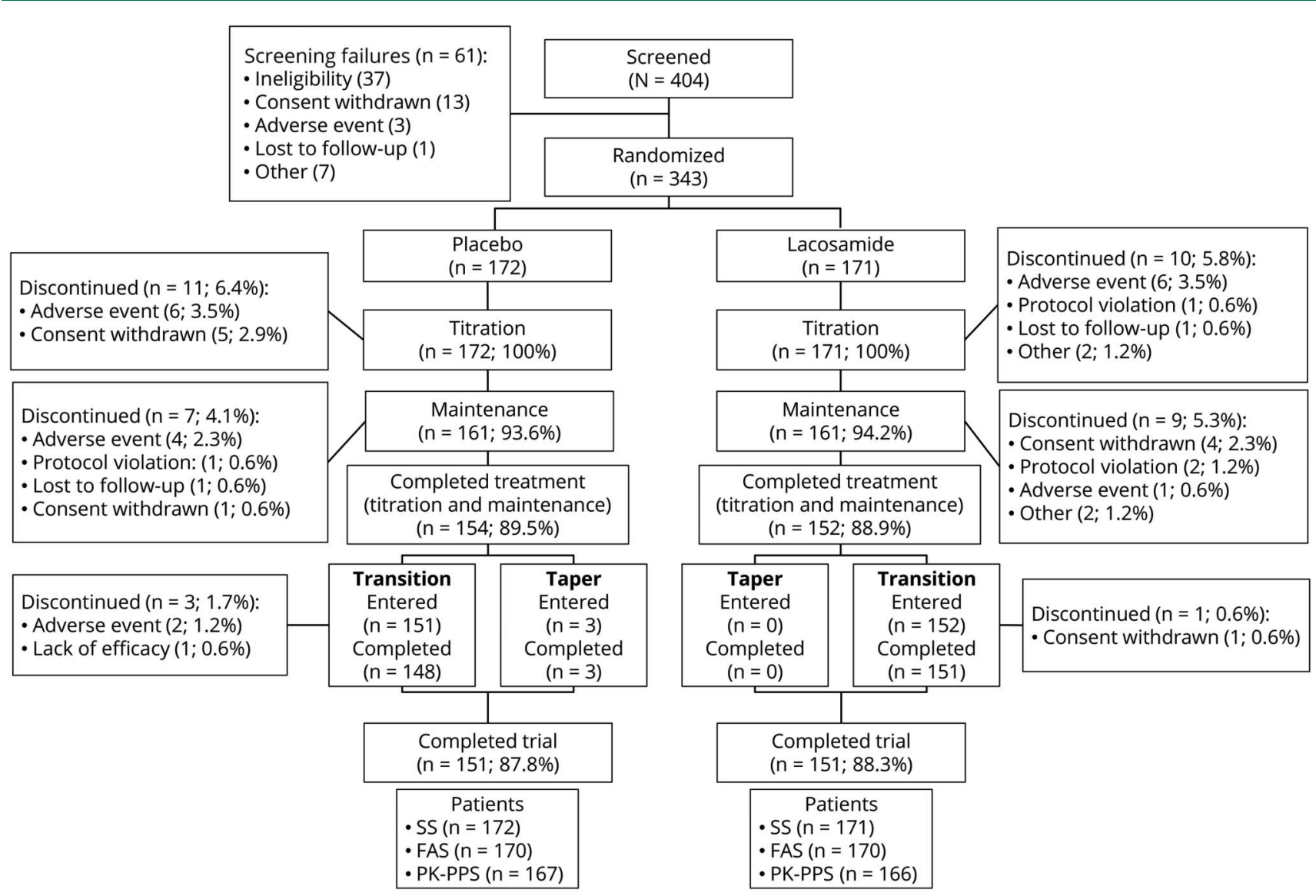

FAS = full analysis set; PK-PPS = pharmacokinetic-per-protocol set; SS = safety set.

treatment (lacosamide: 7 [4.1\%]; placebo: $10[5.8 \%])$. One hundred fifty-one $(88.3 \%)$ patients on lacosamide and 148 (86.0\%) patients on placebo planned to continue to the openlabel extension trial.

Baseline demographic data and epilepsy characteristics were similar between treatment groups (table 1). The majority of patients $(267[77.8 \%])$ were white. Patients had a median epilepsy duration of 6.0 years and a median age at diagnosis of 3.9 years. On the day of first trial dose, the majority of patients were taking 2 or 3 concomitant AEDs (table 1 ). Valproate and levetiracetam were the most common concomitant AEDs. Most patients (224 [65.3\%]) took at least 1 SCB AED.

During titration, most patients (lacosamide: 142 [83.0\%]; placebo: 156 [90.7\%]) did not require any back-titration step. The median of the median daily dose of lacosamide during maintenance was $12 \mathrm{mg} / \mathrm{kg} / \mathrm{d}$ for patients weighing $<30 \mathrm{~kg}, 8 \mathrm{mg} / \mathrm{kg} / \mathrm{d}$ for those weighing $\geq 30$ to $<50 \mathrm{~kg}$, and $400 \mathrm{mg} / \mathrm{d}$ for those weighing $\geq 50 \mathrm{~kg}$. One hundred $(58.5 \%)$ patients on lacosamide and 161 (93.6\%) on placebo reached the maximum target dose level for their weight. A higher proportion of lacosamide-treated patients with 1 concomitant AED at baseline (22 of $30[73.3 \%]$ ) than those with 2
(45 of $78[57.7 \%])$ or 3 (33 of 63 [52.4\%]) concomitant AEDs reached their maximum target dose level. The maximum target lacosamide dose was reached by 38 of 55 (69.1\%) patients not on concomitant SCB AEDs and 62 of 116 (53.4\%) of those on $\geq 1$ SCB AED.

\section{Efficacy}

Three hundred forty patients had postbaseline seizure frequency data and were included in the full analysis set (figure 2 ). At baseline, the median focal seizure frequency per 28 days was 10.41 for patients randomized to lacosamide and 8.77 for those randomized to placebo (table 2). The percent reduction for lacosamide vs placebo in focal seizure frequency per 28 days was $31.72 \%(p=0.0003)$ during maintenance and $30.18 \%(p<0.0001)$ during treatment (table 2). The median percent reductions from baseline to maintenance in focal seizure frequency per 28 days were $51.7 \%$ and $21.7 \%$ for lacosamide and placebo, respectively (figure 3). Generally similar responses were observed during the entire treatment period (figure e- 1 available from Dryad, doi.org/10.5061/dryad.kt5jj49).

The proportions of $50 \%$ and $75 \%$ responders during the maintenance period were higher with lacosamide vs placebo 
Table 1 Baseline demographics and epilepsy characteristics (safety set)

\begin{tabular}{|c|c|c|c|}
\hline & Placebo $(n=172)$ & Lacosamide $(n=171)$ & All patients $(n=343)$ \\
\hline \multicolumn{4}{|l|}{ Patient demographics } \\
\hline Age, mean (SD), y & $10.9(3.5)$ & $10.5(3.6)$ & $10.7(3.5)$ \\
\hline Male, n (\%) & $99(57.6)$ & $91(53.2)$ & $190(55.4)$ \\
\hline BMI, median (range), kg/m² & $18.55(11.1-55.8)^{a}$ & $18.50(10.3-38.1)^{a}$ & $18.50(10.3-55.8)^{\mathrm{b}}$ \\
\hline \multicolumn{4}{|l|}{ Weight band, n (\%) } \\
\hline$<30$ kg & $52(30.2)$ & $61(35.7)$ & $113(32.9)$ \\
\hline$\geq 30 \mathrm{~kg}-<50 \mathrm{~kg}$ & $60(34.9)$ & $46(26.9)$ & $106(30.9)$ \\
\hline$\geq 50 \mathrm{~kg}$ & $60(34.9)$ & $64(37.4)$ & $124(36.2)$ \\
\hline \multicolumn{4}{|l|}{ Epilepsy history } \\
\hline Age at diagnosis, median (range), y & $4.55(0.0-15.6)$ & $3.59(0.0-15.2)$ & $3.92(0.0-15.6)$ \\
\hline Epilepsy duration, median (range), y & $6.04(0.4-16.2)$ & $6.00(0.4-15.7)$ & $6.02(0.4-16.2)$ \\
\hline \multicolumn{4}{|l|}{ Classification of seizures experienced at any point before trial entry ${ }^{c, d}$} \\
\hline Any partial-onset seizures (focal), $n$ (\%) & $172(100)$ & $171(100)$ & $343(100)$ \\
\hline Simple partial (focal aware) & $85(49.4)$ & $94(55.0)$ & $179(52.2)$ \\
\hline Complex partial (focal impaired awareness) & $131(76.2)$ & $134(78.4)$ & $265(77.3)$ \\
\hline Partial evolving to secondarily generalized (focal to bilateral tonic-clonic) & $104(60.5)$ & $111(64.9)$ & $215(62.7)$ \\
\hline Any generalized seizures, $\mathrm{n}(\%)$ & $1(0.6)$ & $4(2.3)$ & $5(1.5)$ \\
\hline Absence & $1(0.6)$ & $2(1.2)$ & $3(0.9)$ \\
\hline Atypical absence & $1(0.6)$ & 0 & $1(0.3)$ \\
\hline Myoclonic & 0 & $2(1.2)$ & $2(0.6)$ \\
\hline Unclassified epileptic seizures, $n$ (\%) & $1(0.6)$ & $1(0.6)$ & $2(0.6)$ \\
\hline \multicolumn{4}{|l|}{ No. of previous AEDs ${ }^{\mathrm{e}}, \mathrm{n}(\%)$} \\
\hline 0 & $63(36.6)$ & $47(27.5)$ & $110(32.1)$ \\
\hline $1-3$ & 79 (45.9) & $94(55.0)$ & $173(50.4)$ \\
\hline $4-6$ & $24(14.0)$ & $25(14.6)$ & $49(14.3)$ \\
\hline$\geq 7$ & $6(3.5)$ & $5(2.9)$ & $11(3.2)$ \\
\hline \multicolumn{4}{|l|}{ Concomitant AEDs ${ }^{\mathrm{f}}$} \\
\hline \multicolumn{4}{|l|}{ No. of concomitant AEDs on day of first trial dose, $n(\%)$} \\
\hline 1 & 29 (16.9) & $30(17.5)$ & $59(17.2)$ \\
\hline 2 & $82(47.7)$ & $78(45.6)$ & $160(46.6)$ \\
\hline 3 & $61(35.5)$ & $63(36.8)$ & $124(36.2)$ \\
\hline \multicolumn{4}{|l|}{ Concomitant AEDs taken by $\geq 10 \%$ of overall population, $n(\%)$} \\
\hline Valproate ${ }^{\mathrm{g}}$ & $86(50.0)$ & $80(46.8)$ & $166(48.4)$ \\
\hline Levetiracetam & $68(39.5)$ & $74(43.3)$ & $142(41.4)$ \\
\hline Carbamazepine & $39(22.7)$ & $50(29.2)$ & $89(25.9)$ \\
\hline Lamotrigine & $41(23.8)$ & $48(28.1)$ & 89 (25.9) \\
\hline Topiramate & $43(25.0)$ & $39(22.8)$ & $82(23.9)$ \\
\hline Oxcarbazepine & $30(17.4)$ & $23(13.5)$ & $53(15.5)$ \\
\hline
\end{tabular}


Table 1 Baseline demographics and epilepsy characteristics (safety set) (continued)

\begin{tabular}{|c|c|c|c|}
\hline & Placebo $(n=172)$ & Lacosamide $(n=171)$ & All patients $(n=343)$ \\
\hline Any concomitant SCB AEDs, $n$ (\%) & $108(62.8)$ & $116(67.8)$ & $224(65.3)$ \\
\hline \multicolumn{4}{|l|}{ Ongoing comorbid conditions at trial entry } \\
\hline Any ongoing medical condition, n (\%) & $108(62.8)$ & $105(61.4)$ & $213(62.1)$ \\
\hline \multicolumn{4}{|l|}{ No. of conditions per patient } \\
\hline Mean (SD) & $2.2(4.0)$ & $2.0(2.7)$ & $2.1(3.5)$ \\
\hline Median (Q1, Q3) & $1.0(0.0,3.0)$ & $1.0(0.0,3.0)$ & $1.0(0.0,3.0)$ \\
\hline $0, \mathrm{n}(\%)$ & $64(37.2)$ & 66 (38.6) & $130(37.9)$ \\
\hline $1, n(\%)$ & $36(20.9)$ & $32(18.7)$ & $68(19.8)$ \\
\hline $2, n(\%)$ & $24(14.0)$ & $21(12.3)$ & $45(13.1)$ \\
\hline$\geq 3, \mathrm{n}(\%)$ & $48(27.9)$ & $52(30.4)$ & $100(29.2)$ \\
\hline \multicolumn{4}{|c|}{ Medical conditions present in $\geq 5 \%$ of overall population, $n(\%)$} \\
\hline Mental retardation & $25(14.5)$ & $22(12.9)$ & $47(13.7)$ \\
\hline Cerebral palsy & $15(8.7)$ & $20(11.7)$ & $35(10.2)$ \\
\hline Hemiparesis & $11(6.4)$ & $12(7.0)$ & $23(6.7)$ \\
\hline Developmental delay & $8(4.7)$ & $9(5.3)$ & $17(5.0)$ \\
\hline \multicolumn{4}{|l|}{ Concomitant non-AED medications ${ }^{\mathrm{h}}$} \\
\hline Any concomitant non-AED, $\mathrm{n}(\%)$ & $83(48.3)$ & $81(47.4)$ & $164(47.8)$ \\
\hline \multicolumn{4}{|c|}{ 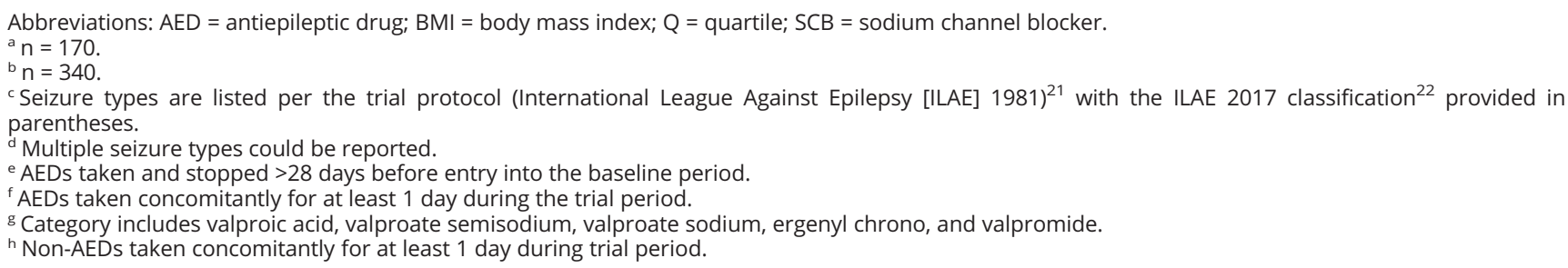 } \\
\hline
\end{tabular}

(figure 3). The mean proportion of seizure-free days during maintenance was 0.71 on lacosamide and 0.66 on placebo (LS mean treatment difference 0.07 (95\% CI 0.029-0.115, $p=$ $0.0011)$. Among patients who completed maintenance, 23 of $152(15.1 \%)$ on lacosamide and 15 of 154 (9.7\%) on placebo were seizure-free. Similar proportions of patients on lacosamide (32 of 170 [18.8\%]) and placebo (39 of 169 [23.1\%]) had a $\geq 25 \%$ increase from baseline to treatment in focal seizure frequency per 28 days.

Subgroup analyses showed similar efficacy of lacosamide in patients with and without concomitant SCB AEDs (table 2 and figure 3 ). Assessments by focal seizure subtype showed reductions in seizure frequency per 28 days with lacosamide vs placebo in simple partial (focal aware), complex partial (focal impaired awareness), and secondarily generalized (focal to bilateral tonic-clonic) seizures, as well as reductions in the combined category of complex partial and/or secondarily generalized seizures (table 2). Higher median percent reductions from baseline in seizure frequency per 28 days and higher 50\% and $75 \%$ responder rates were also observed with lacosamide vs placebo for these focal seizure subtypes (figure e-2 available from Dryad, doi.org/10.5061/dryad.kt5jj49).

\section{Safety and tolerability}

One hundred sixteen (67.8\%) patients on lacosamide and 100 (58.1\%) on placebo reported TEAEs during the treatment period (table 3). As judged by the investigator, these TEAEs were drug related in $54(31.6 \%)$ patients on lacosamide and $31(18.0 \%)$ on placebo. Most TEAEs were mild or moderate in intensity; $5(2.9 \%)$ patients on lacosamide and $6(3.5 \%)$ on placebo reported severe TEAEs. In both treatment groups, the incidences of TEAEs and drug-related TEAEs were higher during titration than maintenance (table 3).

In the lacosamide group, somnolence and dizziness were the most common TEAEs ( $\geq 10 \%$ of patients) and the most common drug-related TEAEs ( $\geq 5 \%$ of patients). Somnolence was reported by 24 (14.0\%) lacosamide-treated patients (34 events) (placebo 9 [5.2\%] patients, 12 events) and was considered to be drug related in $21(12.3 \%)$ patients on 
Table 2 Reduction in focal seizure frequency per 28 days (full analysis set)

\begin{tabular}{|c|c|c|c|c|c|}
\hline & & \multicolumn{2}{|c|}{ Baseline to maintenance } & \multicolumn{2}{|c|}{ Baseline to treatment } \\
\hline & & $\begin{array}{l}\text { Placebo } \\
(n=170)\end{array}$ & $\begin{array}{l}\text { Lacosamide } \\
(n=170)\end{array}$ & $\begin{array}{l}\text { Placebo } \\
(n=170)\end{array}$ & $\begin{array}{l}\text { Lacosamide } \\
(n=170)\end{array}$ \\
\hline \multicolumn{6}{|l|}{ Overall } \\
\hline Focal seizures, $\mathbf{n}$ & & 168 & 170 & 169 & 170 \\
\hline Baseline seizure frequency per $28 \mathrm{~d}$, median & & 8.77 & 10.41 & 8.69 & 10.41 \\
\hline Seizure frequency per $28 \mathrm{~d}$ during assessed trial period, media & $a^{a}$ & 8.71 & 6.36 & 9.33 & 6.46 \\
\hline Percent reduction vs placebo $(95 \% \mathrm{Cl}), p$ value & & \multicolumn{2}{|c|}{$31.72(16.342-44.277) ; p=0.0003$} & \multicolumn{2}{|c|}{$30.18(17.490-40.919) ; p<0.0001$} \\
\hline \multicolumn{6}{|l|}{ Assessments by focal seizure subtype } \\
\hline \multicolumn{2}{|l|}{ Simple partial (focal aware), $\mathrm{n}^{\mathbf{b}}$} & 67 & 77 & 68 & 77 \\
\hline \multicolumn{2}{|l|}{ Baseline seizure frequency per $28 \mathrm{~d}$, median } & 5.78 & 7.50 & 5.39 & 7.50 \\
\hline \multicolumn{2}{|l|}{ Seizure frequency per $28 \mathrm{~d}$ during assessed trial period, median ${ }^{a}$} & 4.67 & 3.11 & 5.75 & 4.71 \\
\hline \multicolumn{2}{|l|}{ Percent reduction vs placebo } & \multicolumn{2}{|c|}{34.58} & \multicolumn{2}{|c|}{30.82} \\
\hline \multicolumn{2}{|l|}{ Complex partial (focal impaired awareness), $\mathrm{n}^{\mathrm{b}}$} & 98 & 109 & 99 & 109 \\
\hline \multicolumn{2}{|l|}{ Baseline seizure frequency per $28 \mathrm{~d}$, median } & 7.50 & 8.30 & 7.50 & 8.30 \\
\hline \multicolumn{2}{|l|}{ Seizure frequency per $28 \mathrm{~d}$ during assessed trial period, median ${ }^{a}$} & 8.19 & 4.67 & 8.11 & 5.45 \\
\hline \multicolumn{2}{|l|}{ Percent reduction vs placebo } & \multicolumn{2}{|c|}{34.67} & & .41 \\
\hline $\begin{array}{l}\text { Partial evolving to secondarily generalized (focal to bilateral } \\
\text { tonic-clonic), } \mathrm{n}^{\mathbf{b}}\end{array}$ & & 69 & 63 & 69 & 63 \\
\hline Baseline seizure frequency per $28 \mathrm{~d}$, median & & 5.31 & 4.50 & 5.31 & 4.50 \\
\hline Seizure frequency per $28 \mathrm{~d}$ during assessed trial period, media & $a^{a}$ & 2.43 & 2.21 & 3.68 & 2.73 \\
\hline Percent reduction vs placebo & & & .75 & & 35 \\
\hline Complex partial/secondarily generalized, $\mathrm{n}^{\mathrm{b}}$ & & 133 & 139 & 134 & 139 \\
\hline Baseline seizure frequency per $28 \mathrm{~d}$, median & & 8.00 & 8.50 & 8.00 & 8.50 \\
\hline Seizure frequency per $28 \mathrm{~d}$ during assessed trial period, media & $a^{a}$ & 7.20 & 4.00 & 8.14 & 5.14 \\
\hline Percent reduction vs placebo & & & 14 & & 7.2 \\
\hline Patients on concomitant SCB AEDs & & $\begin{array}{l}\text { Placebo } \\
(n=107)\end{array}$ & $\begin{array}{l}\text { Lacosamide } \\
(n=115)\end{array}$ & $\begin{array}{l}\text { Placebo } \\
(n=107)\end{array}$ & $\begin{array}{l}\text { Lacosamide } \\
(\mathrm{n}=115)\end{array}$ \\
\hline Focal seizures, $\mathbf{n}$ & & 106 & 115 & 107 & 115 \\
\hline Baseline seizure frequency per $28 \mathrm{~d}$, median & & 9.00 & 15.00 & 9.00 & 15.00 \\
\hline Seizure frequency per $28 \mathrm{~d}$ during assessed trial period, median ${ }^{a}$ & & 7.20 & 7.60 & 7.93 & 7.59 \\
\hline Percent reduction vs placebo & & & 43 & & 8.19 \\
\hline Patients not on concomitant SCB AEDs & $\begin{array}{l}\text { Placeb } \\
63)\end{array}$ & o $(n=$ & samide $(\mathbf{n}=$ & $\begin{array}{l}\text { Placebo }(n= \\
63)\end{array}$ & cosamide $(n=$ \\
\hline Focal seizures, $\mathbf{n}$ & 62 & & & 62 & \\
\hline Baseline seizure frequency per $28 \mathrm{~d}$, median & 8.25 & & & 8.25 & 81 \\
\hline $\begin{array}{l}\text { Seizure frequency per } 28 \mathrm{~d} \text { during assessed trial period, } \\
\text { median }^{\mathrm{a}}\end{array}$ & 12.15 & & & 11.86 & 75 \\
\hline Percent reduction vs placebo & & & & & \\
\hline
\end{tabular}

Abbreviations: $\mathrm{Cl}$ = confidence interval; SCB AED = sodium channel-blocking antiepileptic drug.

a Maintenance or treatment period.

${ }^{b}$ Seizure types are listed per the trial protocol (International League Against Epilepsy [ILAE] 1981) ${ }^{21}$ with the ILAE 2017 classification ${ }^{22}$ provided in parentheses. 


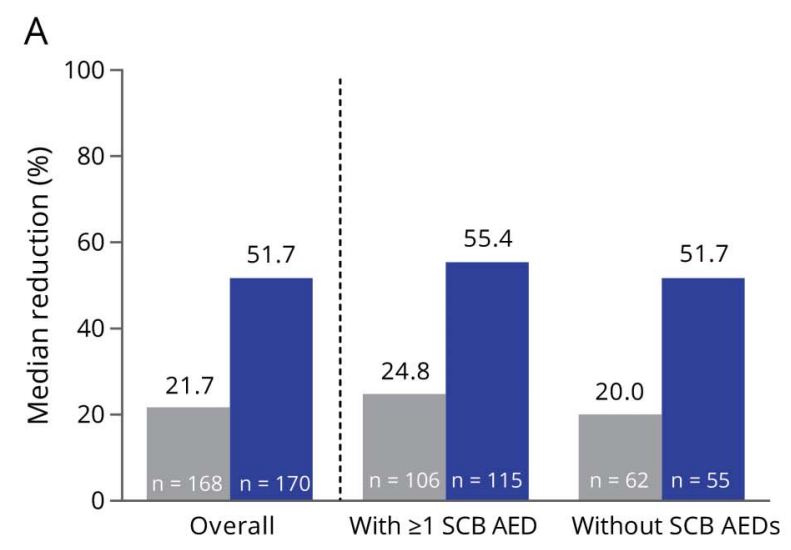

$$
\text { C }
$$

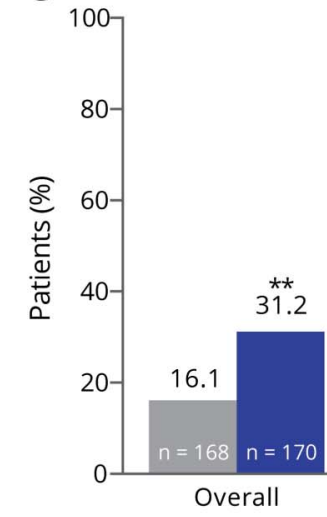

Odds ratio for

lacosamide vs 2.25

placebo: $\quad p=0.0027$

\section{B}

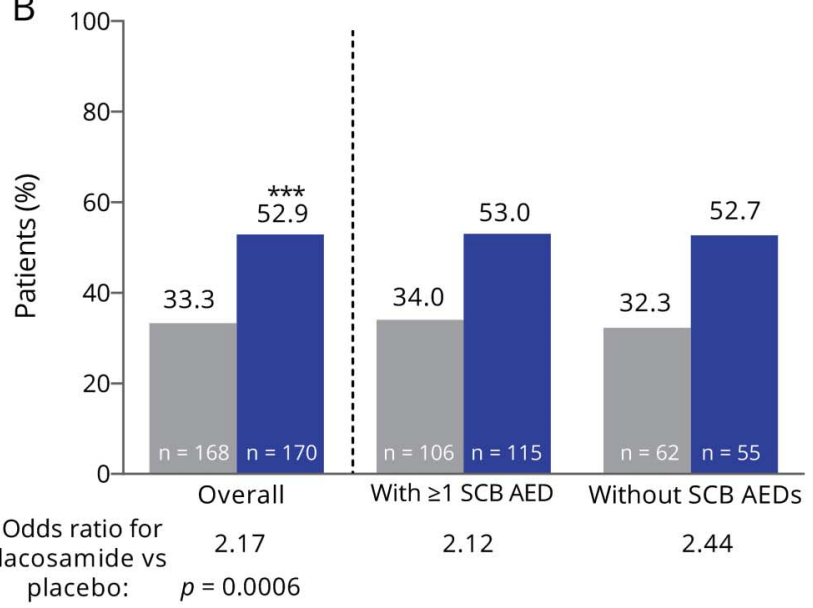

Odds ratio for

placebo: $\quad p=0.0006$

Placebo

Lacosamide

(A) Median percent reduction from baseline, (B) $50 \%$ responder rates, and (C) $75 \%$ responder rates, assessed for the overall population and for patients with and without concomitant sodium channel-blocking antiepileptic drugs (SCB AEDs). ${ }^{* \star} p \leq 0.01,{ }^{* \star *} p \leq 0.001$.

lacosamide (placebo: 8 [4.7\%]). All events of somnolence were mild or moderate in intensity. One patient discontinued lacosamide due to somnolence. The median time from lacosamide initiation to onset of somnolence was 24.0 days (placebo 6.0 days), with a median dose at somnolence onset of $8.0 \mathrm{mg} / \mathrm{kg} / \mathrm{d}$ among patients in the $<30 \mathrm{~kg}$ and 30 to $<50 \mathrm{~kg}$ weight bands and $225 \mathrm{mg} / \mathrm{d}$ among patients weighing $\geq 50 \mathrm{~kg}$. The median duration of somnolence during treatment was 6.0 days on lacosamide and 9.5 days on placebo.

Eighteen (10.5\%) patients on lacosamide reported a total of 22 events of dizziness (placebo 6 [3.5\%] patients, 6 events). Dizziness was considered to be drug related in 15 (8.8\%) patients on lacosamide and 4 (2.3\%) on placebo. All events were mild to moderate in intensity, and none led to trial discontinuation. The median time from lacosamide initiation to onset of dizziness was 26.5 days (placebo 38.5 days), with a median dose at onset of $6.0 \mathrm{mg} / \mathrm{kg} / \mathrm{d}$ for patients weighing 30 to $<50 \mathrm{~kg}$ and $350 \mathrm{mg} / \mathrm{d}$ for patients weighing $\geq 50 \mathrm{~kg}$. The median duration of dizziness during treatment was 7.5 days on lacosamide and 12.5 days on placebo.
Psychiatric TEAEs were reported by $11(6.4 \%)$ patients in each treatment group. Insomnia was the most common psychiatric TEAE, reported by 4 (2.3\%) patients on lacosamide and $2(1.2 \%)$ patients on placebo (table 3 ). Two patients (1.2\%) treated with lacosamide had a total of 3 events of suicidal ideation. These events were mild in intensity, were resolved, and were not related to trial medication as assessed by the trial investigator. There were no suicide attempts during the trial. Severe psychiatric TEAEs were reported by 1 patient on placebo only (severe auditory hallucinations). No patients reported TEAEs related to psychotic disorders, memory impairment, amnesia, or cognitive disorders.

Similar incidences of serious TEAEs were observed in patients on lacosamide $(8[4.7 \%])$ and placebo $(10[5.8 \%])$, and none were considered to be drug-related (table 3 ). Convulsion was the only serious TEAE reported by $\geq 2$ patients (lacosamide: 2 [1.2\%]; placebo: $3[1.7 \%]$ ). A serious TEAE of syncope was reported by 1 patient while on a dose of $5.5 \mathrm{mg} / \mathrm{kg} / \mathrm{d}$ lacosamide. This TEAE was moderate in intensity, did not lead to a dose change, and resolved. The patient experienced a second TEAE of 
Table 3 TEAEs during the titration, maintenance, and treatment periods (safety set)

\begin{tabular}{|c|c|c|c|c|c|c|}
\hline \multirow[b]{2}{*}{ Patients, n (\%) } & \multicolumn{2}{|c|}{ Titration period } & \multicolumn{2}{|c|}{ Maintenance period } & \multicolumn{2}{|c|}{$\begin{array}{l}\text { Treatment period } \\
\text { (titration and } \\
\text { maintenance) }\end{array}$} \\
\hline & $\begin{array}{l}\text { Placebo } \\
(\mathrm{n}=172)\end{array}$ & $\begin{array}{l}\text { Lacosamide } \\
(n=171)\end{array}$ & $\begin{array}{l}\text { Placebo } \\
\text { ( } n=161)\end{array}$ & $\begin{array}{l}\text { Lacosamide } \\
(n=161)\end{array}$ & $\begin{array}{l}\text { Placebo } \\
\text { ( } n=172)\end{array}$ & $\begin{array}{l}\text { Lacosamide } \\
(n=171)\end{array}$ \\
\hline Any TEAEs, $\mathrm{n}(\%)$ & $78(45.3)$ & $96(56.1)$ & $53(32.9)$ & $71(44.1)$ & $\begin{array}{l}100 \\
(58.1)\end{array}$ & $116(67.8)$ \\
\hline Drug-related TEAEs & $28(16.3)$ & $50(29.2)$ & $8(5.0)$ & $17(10.6)$ & $31(18.0)$ & $54(31.6)$ \\
\hline Serious TEAEs & $4(2.3)$ & $5(2.9)$ & $7(4.3)$ & $4(2.5)$ & $10(5.8)$ & $8(4.7)$ \\
\hline Drug-related serious TEAEs & 0 & 0 & 0 & 0 & 0 & 0 \\
\hline Severe TEAEs & $3(1.7)$ & $5(2.9)$ & $3(1.9)$ & $1(0.6)$ & $6(3.5)$ & $5(2.9)$ \\
\hline Discontinuations due to TEAEs & $8(4.7)$ & $6(3.5)$ & $3(1.9)$ & $1(0.6)$ & $10(5.8)$ & $7(4.1)$ \\
\hline Deaths & 0 & 0 & 0 & 0 & 0 & 0 \\
\hline \multicolumn{7}{|c|}{$\begin{array}{l}\text { TEAEs reported by } \geq 5 \% \text { of patients in either treatment group } \\
\text { during the treatment period, } n(\%)\end{array}$} \\
\hline Somnolence & $9(5.2)$ & $20(11.7)$ & 0 & $5(3.1)$ & $9(5.2)$ & $24(14.0)$ \\
\hline Dizziness & $4(2.3)$ & $17(9.9)$ & $2(1.2)$ & $2(1.2)$ & $6(3.5)$ & $18(10.5)$ \\
\hline Nasopharyngitis & $6(3.5)$ & $13(7.6)$ & $1(0.6)$ & $6(3.7)$ & $7(4.1)$ & $17(9.9)$ \\
\hline Vomiting & $4(2.3)$ & $10(5.8)$ & $3(1.9)$ & $7(4.3)$ & $7(4.1)$ & $15(8.8)$ \\
\hline Pyrexia & $3(1.7)$ & $9(5.3)$ & $4(2.5)$ & $6(3.7)$ & $7(4.1)$ & $14(8.2)$ \\
\hline Headache & $7(4.1)$ & $8(4.7)$ & $7(4.3)$ & $4(2.5)$ & $11(6.4)$ & $11(6.4)$ \\
\hline Upper respiratory tract infection & $5(2.9)$ & $6(3.5)$ & $6(3.7)$ & $3(1.9)$ & $10(5.8)$ & $8(4.7)$ \\
\hline \multicolumn{7}{|c|}{$\begin{array}{l}\text { Psychiatric TEAEs reported by } \geq 1 \% \text { of patients in either } \\
\text { treatment group during the treatment period, } n(\%)\end{array}$} \\
\hline Insomnia & $2(1.2)$ & $2(1.2)$ & $1(0.6)$ & $2(1.2)$ & $2(1.2)$ & $4(2.3)$ \\
\hline Sleep disorder & 0 & $2(1.2)$ & 0 & 0 & 0 & $2(1.2)$ \\
\hline Suicidal ideation & 0 & $2(1.2)$ & 0 & $1(0.6)$ & 0 & $2(1.2)$ \\
\hline Aggression & $2(1.2)$ & 0 & 0 & 0 & $2(1.2)$ & 0 \\
\hline Emotional disorder & $2(1.2)$ & 0 & 0 & 0 & $2(1.2)$ & 0 \\
\hline \multicolumn{7}{|c|}{$\begin{array}{l}\text { TEAEs leading to discontinuation in } \geq 1 \% \text { of patients in either } \\
\text { treatment group during the treatment period, } n(\%)\end{array}$} \\
\hline Vertigo & 0 & $2(1.2)$ & 0 & 0 & 0 & $2(1.2)$ \\
\hline Diplopia & 0 & $1(0.6)$ & 0 & $1(0.6)$ & 0 & $2(1.2)$ \\
\hline Increased alanine aminotransferase & $2(1.2)$ & $1(0.6)$ & 0 & 0 & $2(1.2)$ & $1(0.6)$ \\
\hline Increased aspartate aminotransferase & $2(1.2)$ & 0 & 0 & 0 & $2(1.2)$ & 0 \\
\hline
\end{tabular}

Abbreviation: TEAE = treatment-emergent adverse event.

syncope 6 days after her final lacosamide dose; this TEAE was considered to be serious but mild in intensity. Neither incident was considered to be related to lacosamide. ECG data showed a slight prolongation of the PR duration and QRS duration (table e-1 available from Dryad, doi.org/10.5061/dryad.kt5jj49). One patient had a serious TEAE of bradycardia while on a dose of 8 $\mathrm{mg} / \mathrm{kg} / \mathrm{d}$ lacosamide; this TEAE was mild in intensity, was not considered to be related to lacosamide, did not lead to a dose change, and resolved. Vital signs assessments before treatment (screening and baseline visits) showed that the patient had a supine pulse rate of 82 to $84 \mathrm{bpm}$. All supine pulse rates recorded at vital signs assessments during treatment were $\geq 66$ bpm, except for the value recorded during the event of bradycardia $(61 \mathrm{bpm})$. None of the patient's ECG parameters showed 
a clear increase during treatment, and most recordings showed a shortened PR duration compared to baseline (table e- 2 available from Dryad, doi.org/10.5061/dryad.kt5jj49).

Few patients in either treatment group (lacosamide 7 [4.1\%]; placebo $10[5.8 \%])$ had a TEAE that led to discontinuation during the treatment period (table 3 ). Discontinuation due to TEAEs was more common during titration than maintenance (table 3), with a median time to discontinuation of 36 days in the lacosamide group and 50 days in the placebo group. Vertigo and diplopia were the only TEAEs leading to discontinuation of lacosamide in $\geq 2$ patients (diplopia $[n=1]$; vertigo $[n=1]$; vertigo and diplopia $[n=1]$; these events were considered drug related), all of whom were receiving concomitant treatment with a SCB AED.

Analyses of tolerability by number of concomitant AEDs did not show any clear trends in the overall incidences of TEAEs, drug-related TEAEs, or discontinuations due to TEAEs (table e-3 available from Dryad, doi.org/10.5061/dryad.kt5jj49). Similar incidences of somnolence were observed in lacosamide-treated patients on 1, 2, or 3 concomitant AEDs, whereas the majority of patients who reported somnolence on placebo were taking 3 concomitant AEDs. The incidence of dizziness on lacosamide appeared to increase with an increasing number of concomitant AEDs.

Analyses by concomitant SCB use showed a higher incidence of drug-related TEAEs in patients taking lacosamide with a concomitant SCB (34.5\%; 16.7\% with placebo) than in those with no SCB AEDs (25.5\%; $20.3 \%$ with placebo) (table 4). The incidence of drug-related somnolence was similar in lacosamide-treated patients who were on and those not on concomitant SCB AEDs, whereas the incidence of drugrelated dizziness was higher in lacosamide-treated patients who were on concomitant SCBs than in those not on SCB AEDs. Discontinuations due to TEAEs were low in lacosamide-treated patients and were similar to those of patients taking placebo regardless of whether SCB AEDs were part of the treatment regimen (on concomitant SCBs: $5.2 \%$ with lacosamide, $6.5 \%$ with placebo; not on SCB AEDs: $1.8 \%$ with lacosamide, $4.7 \%$ with placebo).

Assessments of behavior and cognitive function showed stable scores over the treatment period. Shifts from baseline to last visit in Achenbach CBCL $1.5-5$ and CBCL/6-18 $\mathrm{T}$-scores were similar in patients on lacosamide and on placebo (table e-4 available from Dryad, doi.org/10.5061/ dryad.kt5jj49), with most patients remaining in their baseline category (normal, borderline, or clinically significant). Of those with a change in category, more improved than worsened. For the BRIEF and BRIEF-Preschool assessments, shifts in $\mathrm{T}$-score findings from baseline to last visit were similar in each treatment group, with very few patients changing category (table e-5 available from Dryad, doi.org/ $10.5061 /$ dryad.kt5jj49). Of those with a change in category, more patients improved than worsened.
No consistent or clinically relevant changes from baseline were observed for hematology, clinical chemistry, or endocrinology parameters, and no clinically relevant changes were observed for vital signs or ECG assessments. Pharmacokinetic data for lacosamide are shown in table e-6 (available from Dryad, doi.org/10.5061/dryad.kt5jj49). For patients on lacosamide, the geometric LS mean ratios for treatment/ baseline and their $90 \%$ CIs were within the $80 \%$ to $125 \%$ limits for valproic acid, levetiracetam, lamotrigine, carbamazepine, topiramate, and oxcarbazepine (MHD) (figure e-3 available from Dryad, doi.org/10.5061/dryad.kt5jj49).

\section{Discussion}

In this double-blind placebo-controlled trial, adjunctive lacosamide was efficacious in reducing seizure frequency and was generally well tolerated in children and adolescents (age $\geq 4-<17$ years) with uncontrolled focal seizures.

A weight-based dosing scheme was used; the maximum dose for each weight band targeted plasma levels shown to be at the upper limit of the therapeutic adjunctive dose in adults (400 $\mathrm{mg} / \mathrm{d}) .^{23}$ This weight-based dosing algorithm and flexible dose escalation during the titration period allowed physicians to tailor lacosamide treatment for each child.

A clinically relevant, significant reduction in focal seizure frequency per 28 days was observed with lacosamide vs placebo from baseline to the maintenance and treatment periods. Secondary and post hoc analyses showed greater median percent reductions from baseline in focal seizure frequency, as well as higher $50 \%$ and $75 \%$ responder rates and higher seizure-freedom rates, with lacosamide compared with placebo. Lacosamide was efficacious regardless of whether SCB AEDs were part of the concomitant treatment regimen. Subgroup analyses indicated the efficacy of lacosamide across all focal seizure types. The efficacy of lacosamide observed in children and adolescents in the current trial was in line with that reported for adults with focal seizures. ${ }^{4-6,24}$ These results further support the concept of extrapolation of efficacy data from adults to the pediatric population with focal seizures. ${ }^{25}$

The 50\% responder rate observed with lacosamide in children $(52.9 \%)$ was consistent with that reported for adults (35\%-49\%); however, the 50\% responder rate with placebo was somewhat higher $(33.3 \%$ vs $22.6 \%){ }^{24}$ This was not unexpected because higher $50 \%$ responder rates for placebo have been observed in children compared with adults. ${ }^{26}$ In this trial, the $50 \%$ responder rate with placebo was comparable to that reported with placebo in a randomized trial of adjunctive zonisamide in children with focal seizures $(31 \%) .^{27}$

The TEAEs most commonly reported during adjunctive lacosamide treatment in children were consistent with AEs 
Table 4 TEAEs during the titration, maintenance, and treatment periods by concomitant SCB AED use (safety set)

\begin{tabular}{|c|c|c|c|c|c|c|c|c|c|c|c|c|}
\hline \multirow[b]{3}{*}{ Patients } & \multicolumn{6}{|c|}{ With $\geq 1$ SCB AED, n (\%) } & \multicolumn{6}{|c|}{ Without SCB AEDs, n (\%) } \\
\hline & \multicolumn{2}{|l|}{ Titration } & \multicolumn{2}{|c|}{ Maintenance } & \multicolumn{2}{|c|}{ Treatment } & \multicolumn{2}{|l|}{ Titration } & \multicolumn{2}{|c|}{ Maintenance } & \multicolumn{2}{|c|}{ Treatment } \\
\hline & $\begin{array}{l}\text { Placebo } \\
(n=108)\end{array}$ & $\begin{array}{l}\text { Lacosamide } \\
(n=116)\end{array}$ & $\begin{array}{l}\text { Placebo } \\
(n=102)\end{array}$ & $\begin{array}{l}\text { Lacosamide } \\
(n=108)\end{array}$ & $\begin{array}{l}\text { Placebo } \\
(n=108)\end{array}$ & $\begin{array}{l}\text { Lacosamide } \\
(n=116)\end{array}$ & $\begin{array}{l}\text { Placebo } \\
(n=64)\end{array}$ & $\begin{array}{l}\text { Lacosamide } \\
(n=55)\end{array}$ & $\begin{array}{l}\text { Placebo } \\
(n=59)\end{array}$ & $\begin{array}{l}\text { Lacosamide } \\
(n=53)\end{array}$ & $\begin{array}{l}\text { Placebo } \\
(n=64)\end{array}$ & $\begin{array}{l}\text { Lacosamide } \\
(n=55)\end{array}$ \\
\hline Any TEAEs & $51(47.2)$ & $60(51.7)$ & $34(33.3)$ & $47(43.5)$ & $64(59.3)$ & $74(63.8)$ & $27(42.2)$ & $36(65.5)$ & $19(32.2)$ & $24(45.3)$ & $36(56.3)$ & $42(76.4)$ \\
\hline Drug-related TEAEs & 15 (13.9) & $36(31.0)$ & $6(5.9)$ & $15(13.9)$ & $18(16.7)$ & $40(34.5)$ & $13(20.3)$ & $14(25.5)$ & $2(3.4)$ & $2(3.8)$ & $13(20.3)$ & $14(25.5)$ \\
\hline Serious TEAEs & $3(2.8)$ & $3(2.6)$ & $5(4.9)$ & $3(2.8)$ & $7(6.5)$ & $5(4.3)$ & $1(1.6)$ & $2(3.6)$ & $2(3.4)$ & $1(1.9)$ & $3(4.7)$ & $3(5.5)$ \\
\hline Discontinuations due to TEAEs & $5(4.6)$ & $5(4.3)$ & $3(2.9)$ & $1(0.9)$ & $7(6.5)$ & $6(5.2)$ & $3(4.7)$ & $1(1.8)$ & 0 & 0 & $3(4.7)$ & $1(1.8)$ \\
\hline \multicolumn{13}{|c|}{$\begin{array}{l}\text { Drug-related TEAEs reported by } \geq 5 \% \text { of } \\
\text { patients in any treatment subgroup } \\
\text { during the treatment period, } n(\%)\end{array}$} \\
\hline Somnolence & $4(3.7)$ & $13(11.2)$ & 0 & $2(1.9)$ & $4(3.7)$ & $15(12.9)$ & $4(6.3)$ & $5(9.1)$ & 0 & $1(1.9)$ & $4(6.3)$ & $6(10.9)$ \\
\hline Dizziness & $2(1.9)$ & $11(9.5)$ & $1(1.0)$ & $2(1.9)$ & $3(2.8)$ & $12(10.3)$ & $1(1.6)$ & $3(5.5)$ & 0 & 0 & $1(1.6)$ & $3(5.5)$ \\
\hline Vomiting & $1(0.9)$ & $5(4.3)$ & 0 & $2(1.9)$ & $1(0.9)$ & $6(5.2)$ & $1(1.6)$ & $1(1.8)$ & 0 & 0 & $1(1.6)$ & $1(1.8)$ \\
\hline Diplopia & 0 & $7(6.0)$ & 0 & $2(1.9)$ & 0 & $7(6.0)$ & 0 & 0 & 0 & 0 & 0 & 0 \\
\hline
\end{tabular}

Abbreviations: SCB AED = sodium channel-blocking antiepileptic drug; TEAE = treatment-emergent adverse event. 
reported during lacosamide treatment in adults (somnolence, dizziness) and with infections frequently encountered in double-blind placebo-controlled trials and openlabel studies of other AEDs in pediatric patients with focal seizures (nasopharyngitis, pyrexia). ${ }^{27-33}$ The incidences of nasopharyngitis and pyrexia were higher with lacosamide than placebo; however, these TEAEs mainly occurred during the titration period, with low incidences $(<4 \%$ of patients) during maintenance. A similar proportion of patients on lacosamide and placebo reported psychiatric TEAEs. The incidence of serious TEAEs was similar on lacosamide and placebo, and few patients in both treatment groups reported severe TEAEs or discontinued because of TEAEs. In both treatment groups, a higher incidence of TEAEs was reported during titration than maintenance, which is consistent with data reported in adults. ${ }^{34}$ This difference was most pronounced for drug-related TEAEs, with $29 \%$ of patients on lacosamide reporting TEAEs in this category during titration vs $11 \%$ during maintenance. However, the initiation and flexible uptitration of lacosamide was generally well tolerated with few patients requiring a dose reduction or discontinuing because of TEAEs. In both treatment groups, analyses of tolerability by number of concomitant AEDs did not show any trends in the overall incidences of TEAEs, drug-related TEAEs, or discontinuations because of TEAEs.

Somnolence and dizziness were the most commonly reported TEAEs, and the most common drug-related TEAEs during adjunctive lacosamide treatment. Somnolence and dizziness occurred mainly during titration, and the duration of these TEAEs was similar between patients on lacosamide and those on placebo. In the lacosamide group, the incidence of somnolence was not related to the number of concomitant AEDs. Drug-related somnolence was reported by similar proportions of patients treated with lacosamide on concomitant SCB AEDs (12.9\%) and those not on SCB AEDs (10.9\%). The incidence of dizziness with lacosamide increased with the number of concomitant AEDs, and the incidence of drug-related dizziness was higher in patients on SCB AEDs (10.3\%) than in those not on SCB AEDs (5.5\%).

Clinical practice experience with adjunctive lacosamide has shown a better ${ }^{35-38}$ or similar ${ }^{39-41}$ tolerability profile in adult patients not on SCB AEDs compared with those on SCB AEDs. A retrospective cohort study of children and adolescents (age <21 years) with focal, generalized, or mixed epilepsy $(n=223)$ showed that use of an SCB AED was an independent predictor of time to lacosamide treatment failure. ${ }^{42}$ Furthermore, analyses of pooled data from double-blind placebo-controlled trials in adults showed a potential for better tolerability of adjunctive lacosamide when taken without SCB AEDs. ${ }^{43}$ Among lacosamide-treated adults on a SCB AED, discontinuations because of AEs were dose-dependent (200 mg, 5.5\%; $400 \mathrm{mg}, 14.4 \%$; $600 \mathrm{mg}, 31.0 \%$ ) and most commonly occurred because of dizziness (7.0\% of patients). ${ }^{43}$ In contrast, adjunctive lacosamide was well tolerated in the current pediatric trial regardless of whether SCB AEDs were part of the treatment regimen. Discontinuation rates were similar for lacosamide and placebo in patients with and without concomitant SCB AEDs, and no patients discontinued because of dizziness. The improved tolerability of adjunctive lacosamide in patients on SCB AEDs in the pediatric trial compared to the trials in adults may be related to the different trial designs. The pediatric trial had a flexible titration schedule with the option of back-titration steps if needed, whereas the adult trials applied forced titration to a predefined randomized dose for each patient. Individualized titration and dosing may allow optimization of tolerability of adjunctive lacosamide treatment in patients taking various AED combinations.

Children with epilepsy have an increased risk for several neurologic (e.g., cognitive impairment) and psychological (e.g., mood disorders, attention-deficit/hyperactivity disorder) disorders, some of which may be linked to the use of AEDs. ${ }^{44}$ The presence of hyperactivity or impulsivity at the time of AED treatment initiation is a predictor of behavioral side effects. ${ }^{45}$ In the current trial, scores for behavior and cognitive function (Achenbach CBCL and BRIEF) were generally stable and similar for both treatment groups, with no worsening for patients on lacosamide vs placebo; however, results for the 4- to 6-year-old group should be interpreted with caution given the small number of patients in this category. Further evaluations are needed to determine the long-term effects of lacosamide on cognition and behavior in children.

In children and adolescents (age $\geq 4-<17$ years) with focal seizures, plasma concentrations of valproic acid, levetiracetam, lamotrigine, carbamazepine, topiramate, oxcarbazepine (MHD), clonazepam, and clobazam were not affected by concomitant lacosamide use. The data for clonazepam and clobazam should be interpreted with caution because of the small sample size. In line with data in adults, ${ }^{46}$ these pharmacokinetic analyses suggest that no dose adjustment for the respective AEDs would generally be needed when lacosamide is added to or removed from the treatment regimen.

In this randomized double-blind trial, adjunctive lacosamide was efficacious in reducing focal seizure frequency in children and adolescents ( $\geq 4$ to $<17$ years of age) with uncontrolled focal seizures and was generally well tolerated with flexible titration and weight-based dosing. These data, together with the favorable, predictable pharmacokinetic profile of lacosamide, its low potential for clinically relevant pharmacokinetic drug-drug interactions, and bioequivalent oral (tablets or oral solution) formulations, ${ }^{3,47}$ demonstrate that lacosamide is a valuable addition to the armamentarium of licensed therapies for focal seizures in pediatric patients. 


\section{Author contributions}

V. Farkas contributed to acquisition of data, analysis or interpretation of data, and drafting/revising the manuscript for content. B. Steinborn contributed to acquisition of data and drafting/revising the manuscript for content. J.R. Flamini contributed to acquisition of data, analysis or interpretation of data, and drafting/revising the manuscript for content. Y. Zhang contributed to analysis or interpretation of data, statistical analyses, and drafting/revising the manuscript for content. N. Yuen contributed to analysis or interpretation of data and drafting/ revising the manuscript for content. S. Borghs, A. Bozorg, and T. Daniels contributed to trial concept or design, analysis or interpretation of data, and drafting/revising the manuscript for content. P. Martin contributed to analysis and interpretation of the post hoc pharmacokinetic data and revising the manuscript for content. H.C. Carney contributed to drafting/revising the manuscript for content. S. Dimova contributed to analysis or interpretation of data and drafting/revising the manuscript for content. I.E. Scheffer contributed to acquisition of data and drafting/revising the manuscript for content.

\section{Acknowledgment}

The authors thank the patients and their caregivers and the clinical project team. Armel Stockis (UCB Pharma, Brainel'Alleud, Belgium) provided input into the post hoc analyses of pharmacokinetic data. Publication management was provided by Barbara Pelgrims, PhD (UCB Pharma, Brussels, Belgium). Deanne Dilley, UCB Pharma, Raleigh, NC, contributed to the statistical analysis.

\section{Study funding}

Supported by UCB Pharma, Brussels, Belgium.

\section{Disclosure}

V. Farkas has participated as principal investigator in UCB Pharma clinical trials. B. Steinborn has participated as principal investigator in UCB Pharma clinical trials and has acted as a speaker for UCB Pharma in Poland. J. Flamini participated as an investigator in the current clinical trial. Y. Zhang, N. Yuen, S. Borghs, A. Bozorg, T. Daniels, P. Martin, and S. Dimova are employees of UCB Pharma. H. Carney provided writing and editorial assistance toward the development of the manuscript, which was contracted by UCB Pharma. I. Scheffer serves on the editorial boards of Neurology ${ }^{\otimes}$ and Epileptic Disorders; may accrue future revenue on a pending patent on a therapeutic compound; has received speaker honoraria from Athena Diagnostics, UCB Pharma, GlaxoSmithKline, Eisai, and Transgenomic; has received scientific advisory board honoraria from Nutricia, BioMarin, and GlaxoSmithKline; has received funding for travel from Athena Diagnostics, UCB Pharma, BioMarin, and GlaxoSmithKline; and receives/has received research support from the Australian National Health and Medical Research Council, ARC, NIH, Health Research Council of New Zealand, March of Dimes, the Weizmann Institute, CURE, the US Department of Defense, and the Perpetual Charitable Trustees. Go to Neurology.org/N for full disclosures.

\section{Publication history}

Received by Neurology October 10, 2018. Accepted in final form April 26, 2019.

\section{Appendix Coinvestigators}

Coinvestigators are listed at links.Iww.com/WNL/A955.

\section{References}

1. Verrotti A, Loiacono G, Coppola G, Spalice A, Mohn A, Chiarelli F. Pharmacotherapy for children and adolescents with epilepsy. Expert Opin Pharmacother 2011;12:175-194.

2. Rogawski MA, Tofighy A, White HS, Matagne A, Wolff C. Current understanding of the mechanism of action of the antiepileptic drug lacosamide. Epilepsy Res 2015;110: 189-205.

3. Cawello W. Clinical pharmacokinetic and pharmacodynamic profile of lacosamide. Clin Pharmacokinet 2015;54:901-914.

4. Ben-Menachem E, Biton V, Jatuzis D, Abou-Khalil B, Doty P, Rudd GD. Efficacy and safety of oral lacosamide as adjunctive therapy in adults with partial-onset seizures. Epilepsia 2007;48:1308-1317.

5. Chung S, Sperling MR, Biton V, et al. Lacosamide as adjunctive therapy for partial-onset seizures: a randomized controlled trial. Epilepsia 2010;51: 958-967.

6. Halász $\mathrm{P}$, Kälviäinen $\mathrm{R}$, Mazurkiewicz-Beldzińska $\mathrm{M}$, et al. Adjunctive lacosamide for partial-onset seizures: efficacy and safety results from a randomized controlled trial. Epilepsia 2009;50:443-453.

7. Wechsler RT, Li G, French J, et al. Conversion to lacosamide monotherapy in the treatment of focal epilepsy: results from a historical-controlled, multicenter, doubleblind study. Epilepsia 2014;55:1088-1098.

8. Baulac M, Rosenow F, Toledo M, et al. Efficacy, safety, and tolerability of lacosamide monotherapy versus controlled-release carbamazepine in patients with newly diagnosed epilepsy: a phase 3, randomised, double-blind, non-inferiority trial. Lancet Neurol 2017;16:43-54.

9. Hong Z, Inoue $\mathrm{Y}$, Liao W, et al. Efficacy and safety of adjunctive lacosamide for the treatment of partial-onset seizures in Chinese and Japanese adults: a randomized, double-blind, placebo-controlled study. Epilepsy Res 2016;127:267-275.

10. Runge U, Arnold S, Brandt C, et al. A noninterventional study evaluating the effectiveness and safety of lacosamide added to monotherapy in patients with epilepsy with partial-onset seizures in daily clinical practice: the VITOBA study. Epilepsia 2015;56: 1921-1930.

11. Steinhoff BJ, Eckhardt K, Doty P, De Backer M, Brunnert M, Schulze-Bonhage A. A long-term noninterventional safety study of adjunctive lacosamide therapy in patients with epilepsy and uncontrolled partial-onset seizures. Epilepsy Behav 2016;58:35-43.

12. Villanueva V, Garcés M, López-Gomáriz E, et al. Early add-on lacosamide in a real-life setting: results of the REALLY study. Clin Drug Investig 2015;35:121-131.

13. Ferreira J, Daniels T, Dilley D, Dimova S, Rice K, Byrnes W. Safety and tolerability of lacosamide as adjunctive therapy in children with partial-onset seizures. [Abstract] Eur J Paediatr Neurol 2015;19(suppl 1):S56-S57.

14. Yuen N, Taeter C, Beller C, Dimova S, Daniels T, Bozorg A. Long-term tolerability of adjunctive lacosamide in pediatric patients aged 4 to $<16$ years with focal seizures: an interim pooled analysis of data from open-label trials. Presented at the 71st Annual Meeting of the American Epilepsy Society; December 1-5, 2017; Washington, DC. Abstract 1.282. Available at: www.aesnet.org. Accessed January 30, 2019.

15. Verrotti A, Loiacono G, Pizzolorusso A, et al. Lacosamide in pediatric and adult patients: comparison of efficacy and safety. Seizure 2013;22:210-216.

16. Grosso S, Parisi P, Spalice A, Verrotti A, Balestri P. Efficacy and safety of lacosamide in infants and young children with refractory focal epilepsy. Eur J of Paediatr Neurol 2014;18:55-59.

17. Pasha I, Kamate M, Didagi SK. Efficacy and tolerability of lacosamide as an adjunctive therapy in children with refractory partial epilepsy. Pediatr Neurol 2014; 51:509-514.

18. Gulati P, Cannell P, Ghia T, et al. Lacosamide as adjunctive therapy in treatmentresistant epilepsy in childhood. J Paediatr Child Health 2015;51:794-797.

19. Kim JS, Kim H, Lim BC, et al. Lacosamide as an adjunctive therapy in pediatric patients with refractory focal epilepsy. Brain Dev 2014;36:510-515.

20. Toupin JF, Lortie A, Major P, et al. Efficacy and safety of lacosamide as an adjunctive therapy for refractory focal epilepsy in paediatric patients: a retrospective single-centre study. Epileptic Disord 2015;17:436-443.

21. Proposal for revised clinical and electroencephalographic classification of epileptic seizures: from the Commission on Classification and Terminology of the International League Against Epilepsy. Epilepsia 1981;22:489-501.

22. Fisher RS, Cross JH, French JA, et al. Operational classification of seizure types by the International League Against Epilepsy: position paper of the ILAE Commission for Classification and Terminology. Epilepsia 2017;58:522-530. 
23. Winkler J, Schoemaker R, Stockis A. Lacosamide population pharmacokinetics in children from 6 months to 17 years of age. [Abstract] Epilepsia 2015;56(suppl 1):177-178.

24. Chung S, Ben-Menachem E, Sperling MR, et al. Examining the clinical utility of lacosamide: pooled analyses of three phase II/III clinical trials. CNS Drugs 2010;24: 1041-1054.

25. Pellock JM, Arzimanoglou A, D'Cruz O, et al. Extrapolating evidence of antiepileptic drug efficacy in adults to children $\geq 2$ years of age with focal seizures: the case for disease similarity. Epilepsia 2017;58:1686-1696.

26. Rheims S, Cucherat M, Arzimanoglou A, Ryvlin P. Greater response to placebo in children than in adults: a systematic review and meta-analysis in drug-resistant partial epilepsy. PLoS Med 2008;5:e166.

27. Guerrini R, Rosati A, Segieth J, Pellacani S, Bradshaw K, Giorgi L. A randomized phase III trial of adjunctive zonisamide in pediatric patients with partial epilepsy. Epilepsia 2013;54:1473-1480.

28. Appleton R, Fichtner K, LaMoreaux L, et al. Gabapentin as add-on therapy in children with refractory partial seizures: a 12-week, multicentre, double-blind, placebo-controlled study: Gabapentin Paediatric Study Group. Epilepsia 1999;40: 1147-1154.

29. Appleton R, Fichtner K, LaMoreaux L, et al. Gabapentin as add-on therapy in children with refractory partial seizures: a 24-week, multicentre, open-label study. Dev Med Child Neurol 2001;43:269-273.

30. Duchowny M, Pellock JM, Graf WD, et al. A placebo-controlled trial of lamotrigine add-on therapy for partial seizures in children: Lamictal Pediatric Partial Seizure Study Group. Neurology 1999;53:1724-1731.

31. Elterman RD, Glauser TA, Wyllie E, Reife R, Wu SC, Pledger G. A double-blind, randomized trial of topiramate as adjunctive therapy for partial-onset seizures in children: Topiramate YP Study Group. Neurology 1999;52:1338-1344.

32. Glauser TA, Nigro M, Sachdeo R, et al. Adjunctive therapy with oxcarbazepine in children with partial seizures: the Oxcarbazepine Pediatric Study Group. Neurology 2000;54:2237-2244.

33. Glauser TA, Ayala R, Elterman RD, et al. Double-blind placebo-controlled trial of adjunctive levetiracetam in pediatric partial seizures. Neurology 2006;66: 1654-1660.

34. Biton V, Gil-Nagel A, Isojarvi J, Doty P, Hebert D, Fountain NB. Safety and tolerability of lacosamide as adjunctive therapy for adults with partial-onset seizures: analysis of data pooled from three randomized, double-blind, placebo-controlled clinical trials. Epilepsy Behav 2015;52:119-127.
35. Foldvary-Schaefer N, Fong JS, Morrison S, Wang L, Bena J. Lacosamide tolerability in adult patients with partial-onset seizures: impact of planned reduction and mechanism of action of concomitant antiepileptic drugs. Epilepsy Behav 2016;57:155-160.

36. Hoefler J, Dobesberger J, Kuchukhidze G, Walser G, Unterberger I, Trinka E. Effect of lacosamide polytherapy with other sodium channel blockers: a retrospective study. [Abstract] Epilepsy Curr 2012;12:361-362.

37. Kamel JT, DeGruyter MA, D'Souza WJ, Cook MJ. Clinical experience with using lacosamide for the treatment of epilepsy in a tertiary centre. Acta Neurol Scand 2013; 127:149-153.

38. Villanueva V, López-Gomáriz E, López-Trigo J, et al. Rational polytherapy with lacosamide in clinical practice: results of a Spanish cohort analysis RELACOVA. Epilepsy Behav 2012;23:298-304.

39. Stephen LJ, Kelly K, Parker P, Brodie MJ. Adjunctive lacosamide in clinical practice: sodium blockade with a difference? Epilepsy Behav 2011;22:499-504.

40. Harden CL, Cohn A, Lowe M, Serrano E. Initial post marketing experience with lacosamide in adult patients with epilepsy. Epilepsy Res 2012;98:260-263.

41. Novy J, Bartolini E, Bell GS, Duncan JS, Sander JW. Long-term retention of lacosamide in a large cohort of people with medically refractory epilepsy: a single centre evaluation. Epilepsy Res 2013;106:250-256.

42. McGinnis E, Kessler SK. Lacosamide use in children with epilepsy: retention rate and effect of concomitant sodium channel blockers in a large cohort. Epilepsia 2016;57:1416-1425.

43. Sake JK, Hebert D, Isojärvi J, et al. A pooled analysis of lacosamide clinical trial data grouped by mechanism of action of concomitant antiepileptic drugs. CNS Drugs 2010;24:1055-1068.

44. Wei SH, Lee WT. Comorbidity of childhood epilepsy. J Formos Med Assoc 2015; 114: 1031-1038.

45. Guilfoyle SM, Follansbee-Junger K, Smith AW, et al. Antiepileptic drug behavioral side effects and baseline hyperactivity in children and adolescents with new onset epilepsy. Epilepsia 2018;59:146-154.

46. Cawello W, Stockis A, Andreas JO, Dimova S. Advances in epilepsy treatment: lacosamide pharmacokinetic profile. Ann NY Acad Sci 2014;1329:18-32.

47. Cawello W, Bökens H, Nickel B, Andreas JO, Halabi A. Tolerability, pharmacokinetics, and bioequivalence of the tablet and syrup formulations of lacosamide in plasma, saliva, and urine: saliva as a surrogate of pharmacokinetics in the central compartment. Epilepsia 2013;54:81-88. 


\section{Neurology}

\section{Efficacy and tolerability of adjunctive lacosamide in pediatric patients with focal seizures}

Viktor Farkas, Barbara Steinborn, J. Robert Flamini, et al.

Neurology 2019;93;e1212-e1226 Published Online before print August 28, 2019

DOI 10.1212/WNL.0000000000008126

This information is current as of August 28, 2019

Updated Information \& Services

References

Subspecialty Collections

Permissions \& Licensing

Reprints including high resolution figures, can be found at: http://n.neurology.org/content/93/12/e1212.full

This article cites 46 articles, 4 of which you can access for free at: http://n.neurology.org/content/93/12/e1212.full\#ref-list-1

This article, along with others on similar topics, appears in the following collection(s):

All Pediatric

http://n.neurology.org/cgi/collection/all_pediatric

Antiepileptic drugs

http://n.neurology.org/cgi/collection/antiepileptic_drugs

Clinical trials Randomized controlled (CONSORT agreement)

http://n.neurology.org/cgi/collection/clinical_trials_randomized_contro

lled_consort_agreement

Partial seizures

http://n.neurology.org/cgi/collection/partial_seizures

Information about reproducing this article in parts (figures,tables) or in its entirety can be found online at:

http://www.neurology.org/about/about_the_journal\#permissions

Information about ordering reprints can be found online:

http://n.neurology.org/subscribers/advertise

Neurology ${ }^{\circledR}$ is the official journal of the American Academy of Neurology. Published continuously since 1951, it is now a weekly with 48 issues per year. Copyright Copyright ( 2019 The Author(s). Published by Wolters Kluwer Health, Inc. on behalf of the American Academy of Neurology.. All rights reserved. Print ISSN: 0028-3878. Online ISSN: 1526-632X.

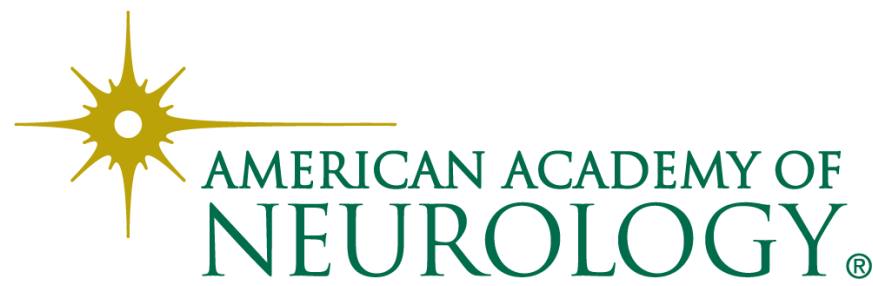

